Article

\title{
Preparation of Carbon Aerogel Electrode for Electrosorption of Copper Ions in Aqueous Solution
}

\author{
Ziling Cao ${ }^{\dagger}$, Chen Zhang ${ }^{\dagger}$, Zhuoxin Yang, Qing Qin, Zhihua Zhang ${ }^{*}$, Xiaodong Wang * ${ }^{\mathbb{D}}$ \\ and Jun Shen *
}

Shanghai Key Laboratory of Special Artificial Microstructure Materials and Technology, Department of Physics Science and Engineering of Tongji University, Shanghai 200092, China; 1653583@tongji.edu.cn (Z.C.); chenzhang_tj@163.com (C.Z.); yangzhuoxin@tongji.edu.cn (Z.Y.); 1653574@tongji.edu.cn (Q.Q.)

* Correspondence: zzhtj@tongji.edu.cn (Z.Z.); xiaodong_wang@tongji.edu.cn (X.W.);

shenjun67@tongji.edu.cn (J.S.); Tel.: +86-021-6598-6071 (Z.Z. \& X.W. \& J.S.)

+ These authors contributed equally to this work.

Received: 21 May 2019; Accepted: 6 June 2019; Published: 9 June 2019

\begin{abstract}
Carbon aerogel (CA) has a rich porous structure, in which micropores and mesopores provide a huge specific surface area to form electric double layers. This property can be applied to the application of capacitive deionization (CDI). The adsorption effect of CA electrode on $\mathrm{Cu}^{2+}$ in an aqueous solution was explored for solving heavy metal water pollution. The CAs were synthesized by a sol-gel process using an atmospheric drying method. The structure of CAs was characterized by scanning in an electron microscope (SEM) and nitrogen adsorption/desorption techniques. The adsorption system was built using $\mathrm{Cu}^{2+}$ solution as the simulation of heavy metal pollution solution. The control variate method was used to investigate the effect of the anion species in copper solution, the molar ratio of resorcinol to catalyst (R/C) of CA, and the applied voltage and concentration of copper ion on the adsorption results.
\end{abstract}

Keywords: carbon aerogel; electrosorption; $\mathrm{Cu}^{2+}$ removal; capacitive deionization

\section{Introduction}

Water is the basis for the survival of all things, but nowadays, the per capita possession of freshwater resources in China is tiny, and these resources have been heavily polluted. Therefore, it is an urgent task to control sewage and achieve secondary utilization. At present, the main ion removal technologies include precipitation, electrolysis, membrane separation, and the ion exchange method [1]. Capacitive deionization (CDI) technology is an emerging desalination technology based on electrosorption. The main principle is that under the action of the electrostatic field, the charged ions in the solution move to the oppositely charged electrodes and enter the inside pores. They then form an electric double layer and are bound to the electrode to purify the solution [2]. Compared with traditional methods, CDI shows the advantages of high efficiency, no secondary pollution, and low cost. Nanoporous carbon aerogel (CA) is an ideal material for the CDI electrode [3,4]. Compared with other carbon materials, CA is highly porous and possesses high electrical conductivity, high electrolyte retention, high specific surface area, and a controllable pore size distribution. It is beneficial to form an electric double layer on the surface of the electrode that attracts a large amount of ions $[5,6]$. Therefore, it has received extensive attention in the field of ion adsorption purification [7-9]. The heavy metal ions in sewage, such as $\mathrm{Cu}^{2+}$, can also be removed by CDI [10-13]. In this paper, $\mathrm{Cu}^{2+}$ was used as the research object to study the application of CDI to remove heavy metal ions in an aqueous solution. CAs with different microstructures were synthesized by the sol-gel method using resorcinol 
and formaldehyde as a precursor. The prepared CA was used as a CDI electrode material to adsorb $\mathrm{Cu}^{2+}$ in aqueous solution, and its application in adsorbing heavy metal ions was explored.

\section{Materials and Methods}

\subsection{Preparation of $C A$}

The CA samples were synthesized by the previously reported technology $[4,10]$. Resorcinol $(R)$ and formaldehyde (F) was used as a precursor in a molar ratio of 1:2, and a sodium carbonate solution, using as catalyst (C), was dissolved in deionized water, stirred for $2 \mathrm{~h}$ to synthesize resorcinol-formaldehyde (RF) into organic sol. The sol was injected into a glass mold, sealed, and placed in a drying oven at $30{ }^{\circ} \mathrm{C}, 50{ }^{\circ} \mathrm{C}$ and $90{ }^{\circ} \mathrm{C}$ for $24 \mathrm{~h}, 24 \mathrm{~h}$ and $72 \mathrm{~h}$, respectively. The obtained RF organic wet gel was soaked with absolute ethanol for $3 \mathrm{~d}$ for solvent-exchange, and the ethanol solvent was renewed once a day. Then, the RF gel was dried at atmospheric pressure in a $50^{\circ} \mathrm{C}$ oven for $3-5$ days to get the RF organic aerogel. The CA was prepared by the carbonization of $\mathrm{RF}$ aerogel at $1000^{\circ} \mathrm{C}$ for $3 \mathrm{~h}$ under $\mathrm{N}_{2}$ atmosphere protection. Then, it was activated at $1000^{\circ} \mathrm{C}$ in a $\mathrm{CO}_{2}$ atmosphere for $2 \mathrm{~h}$. The molar ratios of resorcinol to catalyst $(\mathrm{R} / \mathrm{C})$ in this paper were $300,500,800,1000$, and 1500 . The mass fraction of $\mathrm{R}$ and $\mathrm{F}$ in the RF organic sol (M\%) was 30. The obtained CA samples were labeled 330, 530, 830, 1030, 1530 , respectively.

\subsection{Characterization}

Morphology detection and pore structure analysis are significant characterization methods for nanoporous materials [14]. The morphology of CAs was characterized by a Plilips XL30 FEG scanning electron microscope (SEM, Royal Dutch Philips Electronics Ltd., Amsterdam, The Netherlands). The particle size and stack of different CAs were compared and analyzed from the SEM images. To more clearly reflect the sample characteristics, the CA samples were sprayed with gold for $80 \mathrm{~s}$ before testing. The specific surface area (SSA) of CAs were tested using a TriStar 3000 nitrogen adsorption analyzer (Micromeritics Instruments Corporation, Norcross, GA, USA) at $77 \mathrm{~K}$ and computed by Brunauer-Emmett-Teller (BET) algorithm, while the pore size distribution was calculated using the Barrett-Joyner-Halenda (BJH) method.

\subsection{Electrochemical and CDI Adsorption Test}

The CA block was crushed and ground into powder by a pulverizer (Yongkang Jiupin Industry and Trading Co. Ltd., Yongkang, China). The CA powders, polyvinylidene fluoride (PVDF) and acetylene black were mixed in a mass ratio of 8:1:1. An appropriate amount of 1-methyl-2-pyrrolidone was added and stirred for $12 \mathrm{~h}$ to prepare CA mixture slurry. The foamed nickel, the current collector for electrochemical tests, with a thickness of $1 \mathrm{~mm}$ was cut into rectangular shapes of $1 \mathrm{~cm} \times 3 \mathrm{~cm}$ and then immersed in alcohol and acetone for $30 \mathrm{~min}$, respectively, to remove impurities on the surface of the foamed nickel. Finally, they were washed with alcohol several times and dried in a cool place. The CA slurry was uniformly coated on the dried foamed nickel with an area of $1 \mathrm{~cm} \times 1 \mathrm{~cm}$. Then these coated foamed nickel sheets were placed in a vacuum oven at $100{ }^{\circ} \mathrm{C}$ for $10 \mathrm{~h}$ and pressed at a pressure of $15 \mathrm{MPa}$ for $20 \mathrm{~s}$ to prepare CA electrodes for the electrochemical test. The electrochemical tests including cyclic voltammetry (CV) and electrochemical impedance spectroscopy (EIS) were performed with a standard three-electrode system, including a reference electrode (calomel electrode), a counter electrode (platinum electrode) and a working electrode (CA electrode). The electrolyte solution was $\mathrm{KOH}$ solution with a concentration of $6 \mathrm{~mol} / \mathrm{L}$.

The prepared CA slurry was uniformly coated on current collector graphite sheets $\left(10 \times 10 \mathrm{~cm}^{2}\right)$ and dried in an oven at $100{ }^{\circ} \mathrm{C}$ under vacuum condition for $10 \mathrm{~h}$ to obtain CA electrodes for CDI experiments. Two same electrodes were mounted to a "sandwich" CDI cell in the order of plexiglass plate, CA electrode, plexiglass frame, glass filament separator, CA electrode, and plexiglass plate. The plexiglass frame with a central hollow kept a separation distance of $5 \mathrm{~mm}$ between the positive 
and negative electrodes. The rubber gaskets were clamped between the plexiglass and the electrode to prevent water leakage (as shown in Figure 1). CDI adsorption experiments were performed in a batch-mode circulatory system shown in Figure 1, which consisted of a CDI cell, solution tank, conductivity meter, peristaltic pump, and a direct current (DC) voltage source. The solution was flowed from the solution tank into the CDI cell and back to the solution tank, forming a circulation system. The solution flow rate was about $25 \mathrm{~mL} / \mathrm{min}$ and constant for all the tests. The DC voltage source was used to provide DC voltage. The conductivity of the solution was detected in real time by the conductivity meter connected to the computer, and the data was recorded every minute.

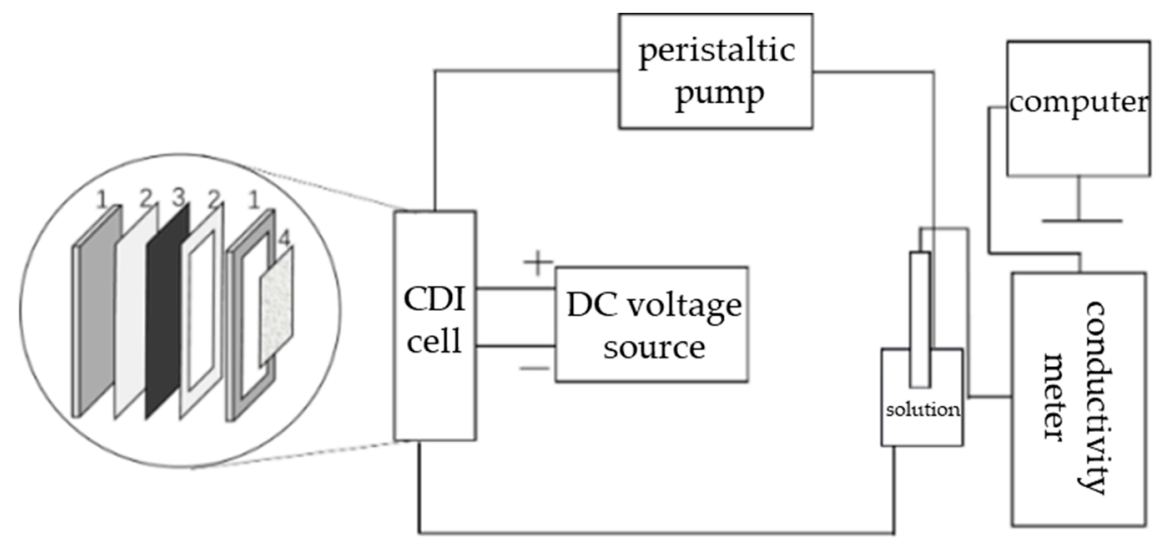

Figure 1. Capacitive deionization (CDI) system diagram and the framework of the CDI cell. Thereinto, 1 is a plexiglass plate as a support plate, 2 is a rubber gasket to prevent the water leakage, 3 is a carbon aerogel (CA) electrode as the working electrode, and 4 is a glass filament separator to prevent short circuiting.

\subsection{Preset of the Copper Solution}

The concentration of the solution is linear with the conductivity in the low concentration range and could be converted by the concentration-conductivity calibration curve. The linear relationships between concentration and conductivity of $\mathrm{CuSO}_{4}, \mathrm{Cu}\left(\mathrm{NO}_{3}\right)_{2}$, and $\mathrm{CuCl}_{2}$ solutions, respectively, are as follows:

$$
\begin{array}{ll}
\mathrm{CuSO}_{4}: & \text { Con. }=28.08392+0.60236 \mathrm{c}, \mathrm{r}_{1}=0.99631 \\
\mathrm{Cu}\left(\mathrm{NO}_{3}\right)_{2}: & \text { Con. }=17.80408+0.94524 \mathrm{c}, \mathrm{r}_{2}=0.99916 \\
\mathrm{CuCl}_{2}: & \text { Con. }=25.39195+1.34801 \mathrm{c}, \mathrm{r}_{3}=0.99957
\end{array}
$$

where c represents the solution concentration $(\mathrm{mg} / \mathrm{L})$, Con. represents the conductivity of the solution $(\mu \mathrm{S} / \mathrm{cm})$, and $r_{1}, r_{2}$ and $r_{3}$ are the correlation coefficients of the linear fitting.

\section{Results and Discussion}

\subsection{Characteristics of $C A$}

\subsubsection{Structural Characterization}

The surface morphology of the electrode material is an important factor affecting the electrosorption capacity. Figure 2 is the SEM image of 330, 530, 830, 1030 and 1530. It can be seen from the figure that CA has a three-dimensional network-like pore structure that is crosslinked by many small particles. The microstructure of CA is regulated and controlled by $\mathrm{R} / \mathrm{C}$. As the $\mathrm{R} / \mathrm{C}$ increases, the carbon particles grow, the pores between particles get larger, and thus, the structures of CAs become looser. When the $\mathrm{M} \%$ is fixed, the larger the $\mathrm{R} / \mathrm{C}$, the smaller the amount of catalyst. As a result, $\mathrm{R}$ and $\mathrm{F}$ in the precursor solution can be sufficiently reacted to form larger particles. Therefore, the pores which are stacked by cross-linking carbon particles are larger, resulting in a looser structure. Table 1 shows the SSA and 
pore structure parameters of 330, 530, 830, 1030, and 1530. With the increase of R/C, the micropore SSA firstly improves and then falls off. The 1030 sample has the largest pore volume $\left(3.41 \mathrm{~cm}^{3} / \mathrm{g}\right)$, micropore SSA $\left(1083 \mathrm{~m}^{2} / \mathrm{g}\right)$, and volume $\left(0.55 \mathrm{~cm}^{3} / \mathrm{g}\right)$, and average pore diameter, which provides the fast pathway for ion transfer that facilitates electrosorption.
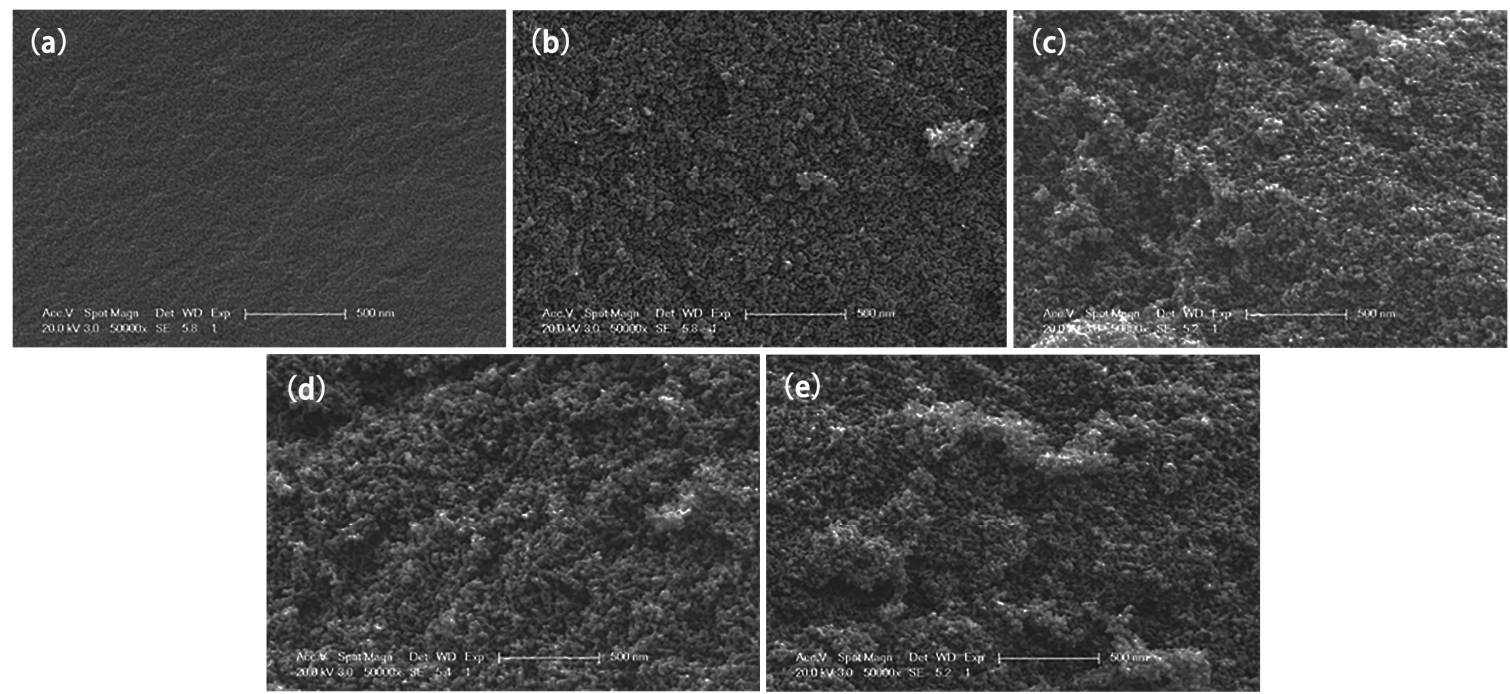

Figure 2. SEM image of different CAs. (a) 330; (b) 530; (c) 830; (d) 1030; (e) 1530 .

Table 1. Specific surface area and pore structure parameters of different CAs.

\begin{tabular}{cccccc}
\hline CAs & $\mathbf{S}_{\text {BET }} \mathbf{1}^{\left.\mathbf{(} \mathbf{m}^{\mathbf{2}} / \mathbf{g}\right)}$ & $\mathbf{S}_{\text {mic }}\left(\mathbf{m}^{\mathbf{2}} / \mathbf{g}\right)$ & $\mathbf{V}_{\mathbf{t}}\left(\mathbf{c m}^{3} / \mathbf{g}\right)$ & $\mathbf{V}_{\text {mic }}\left(\mathbf{c m}^{3} / \mathbf{g}\right)$ & $\mathbf{D}_{\text {ave }}(\mathbf{n m})$ \\
\hline 330 & 832 & 416 & 0.36 & 0.21 & 3.5 \\
530 & 2177 & 819 & 3.0 & 0.41 & 8.6 \\
830 & 1496 & 928 & 1.77 & 0.46 & 11.3 \\
1030 & 2057 & 1083 & 3.41 & 0.55 & 13.3 \\
1530 & 2188 & 920 & 2.87 & 0.45 & 9.4
\end{tabular}

${ }^{1} \mathrm{~S}_{\mathrm{BET}}$ : SSA calculated by multi-point BET method; $\mathrm{S}_{\text {mic }}, \mathrm{V}_{\text {mic }}$ : Micropore SSA and volume obtained using t-plot calculation; $\mathrm{V}_{\mathrm{t}}$ : Total pore volume; $\mathrm{D}_{\text {ave }}$ : Average pore diameter.

\subsubsection{Electrochemical Tests}

Figure 3a displays the $\mathrm{CV}$ curves of $\mathrm{CA}$ samples with different $\mathrm{R} / \mathrm{C}$ in $6 \mathrm{~mol} / \mathrm{L} \mathrm{KOH}$ solution at the scan rate of $10 \mathrm{mV} / \mathrm{s}$. It can be found that almost all the curves show symmetrical rectangular shape, indicating that the $\mathrm{CA}$ electrodes have excellent electric double layer performance. There are no obvious redox peaks in the five curves, which manifests that no redox reaction and faradaic pseudo-capacitance occur. It is further demonstrated that ions are trapped in the electrode by forming an electric double layer during electrosorption. The specific capacitance SC of each CA electrode can be calculated as follows:

$$
\mathrm{SC}=\int I d V /(\mathrm{m} \cdot \mathrm{v})
$$

where $I$ is the current $(\mathrm{A}), V$ is the voltage $(\mathrm{V}), \mathrm{m}$ is the mass of CA in the electrode material $(\mathrm{g})$, and $\mathrm{v}$ is the scan rate $(\mathrm{V} / \mathrm{s})$. The specific capacitance of CA samples with different $\mathrm{R} / \mathrm{C}$ is shown in Table 2. The specific capacitance tends to increase first and then decrease with the increase of R/C. The specific capacity of the 1530 sample is significantly reduced. The 1030 sample has the largest specific capacitance, attaining $156 \mathrm{~F} / \mathrm{g}$ (at the scan rate of $10 \mathrm{mV} / \mathrm{s}$ ), indicating that 1030 has the best electrosorption performance. The variation trend of specific capacitance for CA electrodes is consistent with the changes in the amount of micropores (Table 1), which proves that the electrosorption performance has a great relationship with the pore volume and micropore amount of aerogel. 


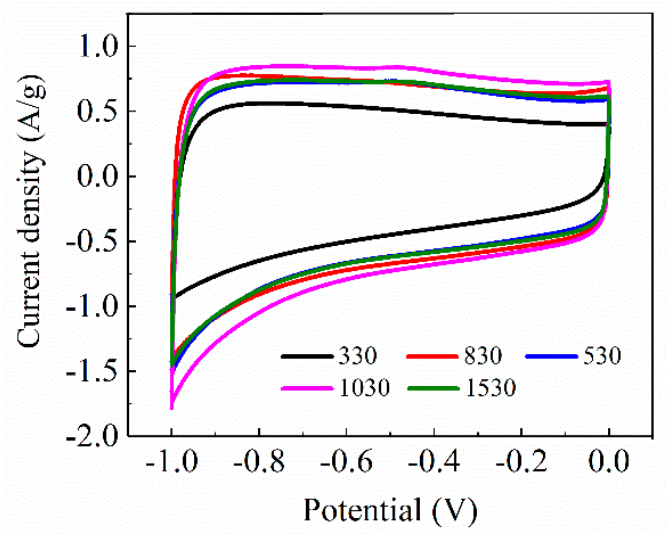

(a)

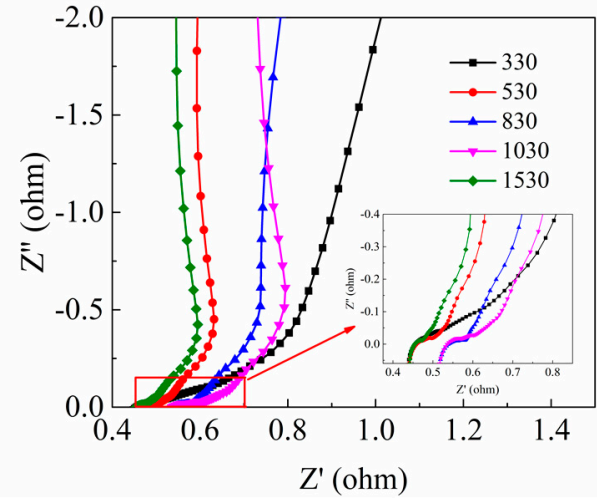

(b)

Figure 3. (a) The cyclic voltammetry (CV) curves of CA samples with different R/C in $6 \mathrm{~mol} / \mathrm{L} \mathrm{KOH}$ solution at the scan rate of $10 \mathrm{mV} / \mathrm{s}$ and $(\mathbf{b})$ the EIS Nyquist plots of CAs with different R/C.

Table 2. The specific capacitance of different CAs.

\begin{tabular}{|c|c|c|c|}
\hline \multirow{2}{*}{$\begin{array}{c}\text { Sample } \\
(\mathrm{R} / \mathrm{C})\end{array}$} & \multicolumn{3}{|c|}{ Specific Capacitance/(F.g $\left.{ }^{-1}\right)$} \\
\hline & $10 \mathrm{mV} \cdot \mathrm{s}^{-1}$ & $50 \mathrm{mV} \cdot \mathrm{s}^{-1}$ & $100 \mathrm{mV} \cdot \mathrm{s}^{-1}$ \\
\hline 330 & 93 & 75 & 65 \\
\hline 530 & 132 & 115 & 106 \\
\hline 830 & 141 & 128 & 118 \\
\hline 1030 & 156 & 135 & 123 \\
\hline 1530 & 133 & 115 & 103 \\
\hline
\end{tabular}

Figure $3 \mathrm{~b}$ shows the EIS Nyquist plots of CAs with different R/C. The semi-circular arc at high frequency represents the charge transfer resistance at the electrode/solution interface. All CA electrodes show very small diameters of the semicircles, suggesting the electrodes have a really small charge transfer resistance. The straight line with a slope of about $45^{\circ}$ in the middle frequency region implies the ion diffusion resistance in the electrode, and the vertical straight line at low frequency reflects the electric double layer capacitance characteristics. The five samples in the figure all show satisfactory shape, indicating that these CA electrodes exhibit good electrical conductivity and excellent electrochemical performance $[15,16]$.

\subsection{Adsorption Results of $\mathrm{Cu}^{2+}$}

\subsubsection{Effect of Anions on Adsorption Capacity}

In order to study the effect of anion species on the adsorption capacity of $\mathrm{CA}, \mathrm{CuSO}_{4}, \mathrm{CuCl}_{2}$ and $\mathrm{Cu}\left(\mathrm{NO}_{3}\right)_{2}$ solutions were used for electrosorption experiments. The $\mathrm{CA}$ electrode used in this part was the 1530 sample. The volume of copper solution was $100 \mathrm{~mL}$, and the concentration was $100 \mathrm{mg} / \mathrm{L}$. Figure 4 shows the electrosorption process of the CA electrode in the copper solutions with different anion species. When a voltage of $1.5 \mathrm{~V}$ is applied, ions in the solution are rapidly adsorbed to the surface of electrodes, and the conductivity of the solution decreases. After some time, the conductivity of the solution reaches equilibrium, and then the electric field is removed. The ions diffuse freely from the electrodes to the solution due to the loss of electrostatic force, and the conductivity increases. Table 3 lists the salt adsorption capacity (SAC) of CA for $\mathrm{Cu}^{2+}$ in the three solutions. The SAC mentioned here is defined as the total mass of ions during the electrosorption, that is, the mass of ions adsorbed per gram of CA. As can be seen from Figure 5 and Table 3, the ion adsorption rate in the solution with $\mathrm{SO}_{4}{ }^{2-}$ is faster than that in the solution with $\mathrm{NO}_{3}{ }^{-}$and $\mathrm{Cl}^{-}$. It is because the valence state of $\mathrm{SO}_{4}{ }^{2-}$ is higher than the other two. As a result, the driving force on ions in the solution with $\mathrm{SO}_{4}{ }^{2-}$ applied by 
the external electric field is stronger, the rate of ions moving toward the electrodes is faster, and the adsorption rate is also higher. The SAC gets sequentially weakened in the solution with $\mathrm{SO}_{4}{ }^{2-}, \mathrm{NO}_{3}{ }^{-}$ and $\mathrm{Cl}^{-}$. In addition, the CDI electrosorption is impacted by the hydrated ionic radius (HIR) and ion mass. The HIR of $\mathrm{NO}_{3}{ }^{-}$and $\mathrm{Cl}^{-}$(335 pm and $332 \mathrm{pm}$, respectively) differs slightly, while the ion mass of $\mathrm{NO}_{3}{ }^{-}(62.004 \mathrm{amu})$ is greater than that of $\mathrm{Cl}^{-}(35.453 \mathrm{amu})$. Thus, the adsorption amount of ions by the $\mathrm{CA}$ electrode in $\mathrm{Cu}\left(\mathrm{NO}_{3}\right)_{2}$ solution is slightly larger than that in the $\mathrm{CuCl}_{2}$ solution. Therefore, in the following experiments, the $\mathrm{CuSO}_{4}$ solution is selected as the adsorption solution.

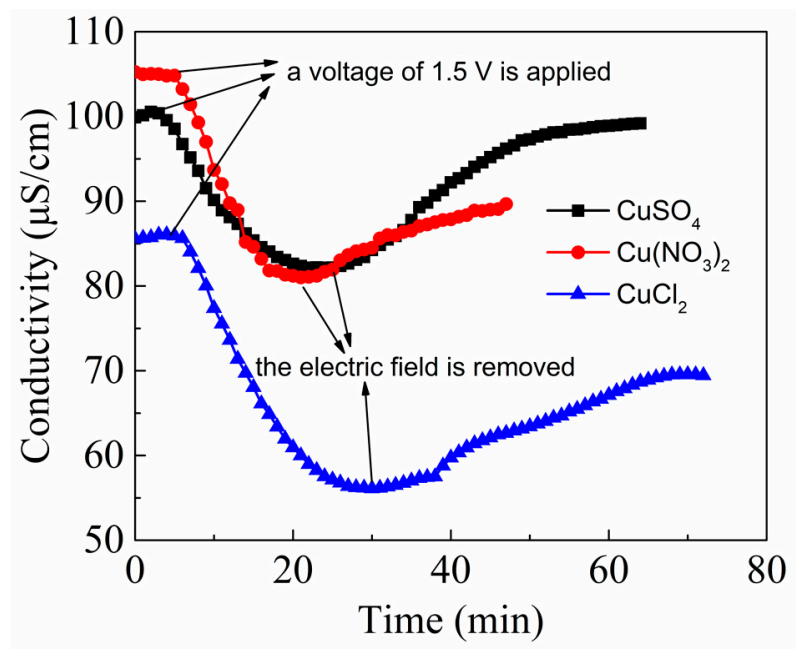

Figure 4. The adsorption curves of CA electrodes for three copper solution.

Table 3. The salt adsorption capacity (SAC) of CA electrodes for different copper solution.

\begin{tabular}{cccc}
\hline Anion Species & $\mathbf{S O}_{4}{ }^{2-}$ & $\mathbf{N O}_{3}{ }^{-}$ & $\mathbf{C l}^{-}$ \\
\hline Concentration $(\mathrm{mg} / \mathrm{L})$ & 100 & 100 & 100 \\
Total SAC at $1.2 \mathrm{~V}(\mathrm{mg} / \mathrm{g})$ & 7.24 & 5.50 & 5.27 \\
\hline
\end{tabular}

\subsubsection{Effect of CA Structure on Adsorption Capacity}

The CA electrodes with different $\mathrm{R} / \mathrm{C}$ were used for $\mathrm{CDI}$ electrosorption experiments in $\mathrm{CuSO}_{4}$ solution with the concentration of $100 \mathrm{mg} / \mathrm{L}$. The applied voltage was $1.2 \mathrm{~V}$, and all samples were subjected to specific adsorption for $1 \mathrm{~h}$ before charging. The adsorption curves are shown in Figure $5 \mathrm{a}$. All curves show a similar trend: the conductivity of the solution decreases slowly at first, while drops rapidly after applying voltage, and finally, do not fall anymore to achieve a minimum. The specific adsorption during an open circuit is due to the reaction of the functional groups on the CA surface with the copper ions. After applying the voltage, the electrosorption occurs and dominates on CA electrodes due to the presence of the electric field force. The SAC of each CA sample is displayed in Figure $5 \mathrm{~b}$. The 1030 sample has the highest SAC, up to $29.7 \mathrm{mg} / \mathrm{g}$. Noked pointed out that micropores were mainly used to store charge during CDI electrosorption [17]. The 1030 sample has the largest amount of micropores, leading to the largest SAC. The 530 sample has the highest salt removal rate $\eta$ (defined as the ratio of the reduction in solution concentration to the initial concentration), probably due to the large amount of CA on the electrode. In this experiment, the maximum removal rate of a single CDI cell can reach $73.6 \%$. It can be predicted that when multiple CDI cells are connected in series, the removal rate of $\mathrm{CA}$ to $\mathrm{Cu}^{2+}$ will achieve a very desirable result. 


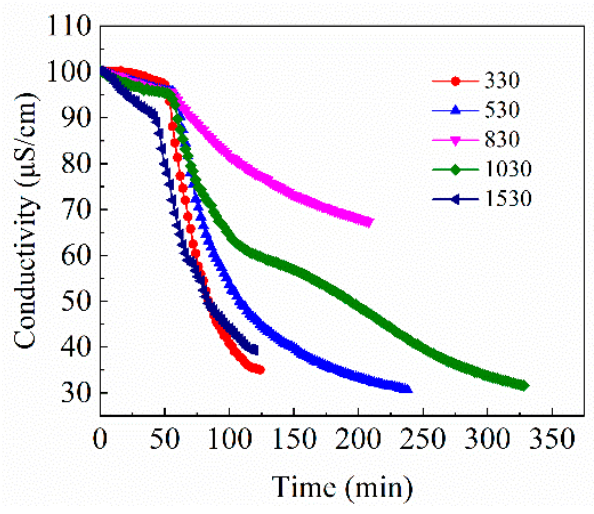

(a)

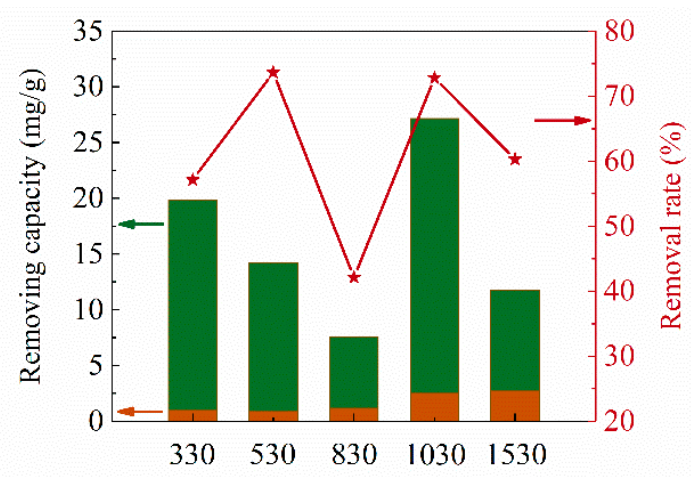

(b)

Figure 5. (a) Adsorption curves and (b) the SAC and removal rate of CAs with different $\mathrm{R} / \mathrm{C}$ in $\mathrm{CuSO}_{4}$ solution. The orange area in (b) represents the specific adsorption during the open circuit, and the green area represents the electrosorption capacity.

\subsubsection{Effect of Applied Voltage and $\mathrm{Cu}^{2+}$ Concentration on Adsorption Capacity}

Operating conditions have a major impact on CDI performance. Therefore, the electrosorption capacity of CA in $\mathrm{CuSO}_{4}$ solution with the concentration of $100 \mathrm{mg} / \mathrm{L}$ under different applied voltage was investigated with the 1030 sample. The adsorption curves under the voltage of $0.4-1.5 \mathrm{~V}$ are displayed in Figure 6a. Since the CA samples are the same, the specific adsorption capacities in the front part of the curves are similar. Under different voltages, the adsorption rate is accelerated, with the increasing voltage due to the intensive electric field force. Combined with the SAC calculation at different voltages in Table 4, the electrosorption capacities of CA climb up and then decline as the applied voltage increases. CA electrode achieves the largest SAC under the applied voltage of $1.2 \mathrm{~V}$. The SAC decreases at $1.5 \mathrm{~V}$, which may be ascribed to the electrolytic reaction of water caused by the too large voltage. The applied voltage is an important factor affecting the adsorption capacity, adsorption rate, and removal rate of the CA electrode. Therefore, for different CDI systems, the corresponding optimal operating voltage should be ascertained.

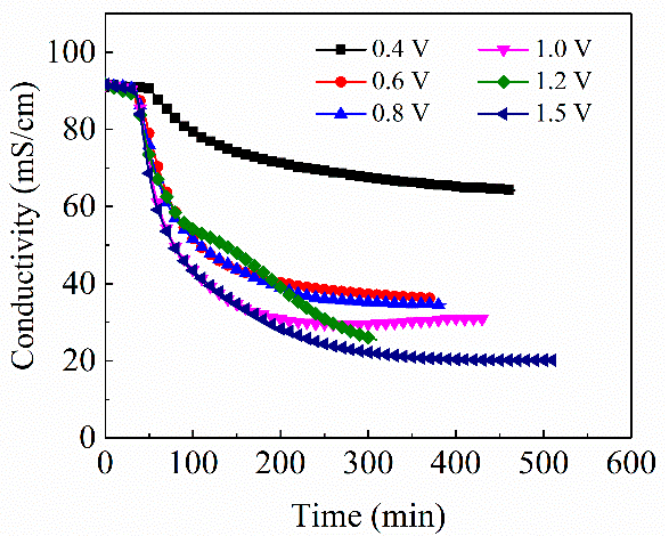

(a)

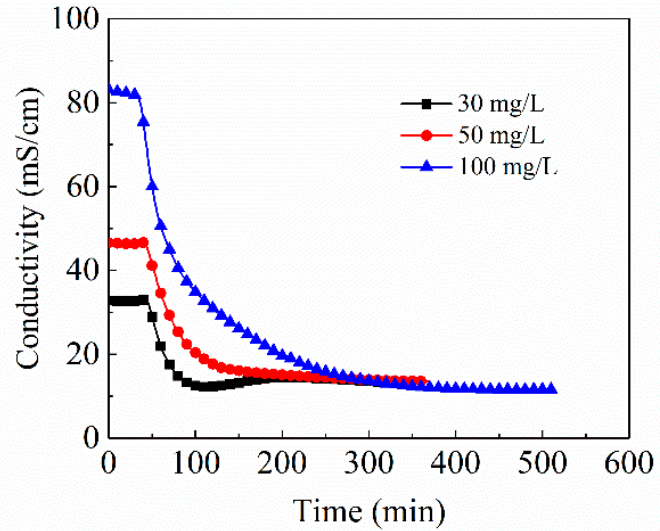

(b)

Figure 6. Adsorption curves of different $\mathrm{CAs}(\mathbf{a})$ for $\mathrm{CuSO}_{4}$ solution and (b) the adsorption curves of carbon aerogel electrode for $\mathrm{CuSO}_{4}$ solution at different voltages. 
Table 4. The SAC and removal rate of CA electrodes for $\mathrm{CuSO}_{4}$ solution at different voltages.

\begin{tabular}{ccc}
\hline Voltage (V) & SAC (mg/g) & $\boldsymbol{\eta} \mathbf{( \% )}$ \\
\hline 0.4 & 15.97 & 31.7 \\
0.6 & 17.36 & 64.3 \\
0.8 & 22.99 & 61.5 \\
1.0 & 17.86 & 72.6 \\
1.2 & 29.70 & 72.8 \\
1.5 & 25.78 & 85.4 \\
\hline
\end{tabular}

In addition to the applied voltage, the concentration of $\mathrm{Cu}^{2+}$ in the solution also affects the $\mathrm{CDI}$ adsorption performance. Figure $6 \mathrm{~b}$ shows the adsorption curves of the same $\mathrm{CA}$ in $\mathrm{CuSO}_{4}$ solution with different concentrations of $30 \mathrm{mg} / \mathrm{L}, 50 \mathrm{mg} / \mathrm{L}$ and $100 \mathrm{mg} / \mathrm{L}$ at the applied voltage of $1.2 \mathrm{~V}$. It can be found that the adsorption rate of copper ions gradually increases with the increase of solution concentration. As the concentration gets larger, the capacity of specific adsorption and total adsorption, and removal rate gradually increases. When the applied voltage is fixed, the move rate of ions toward the electrode surface is similar. The higher the concentration of the solution, the more the number of ions moving toward the electrode per unit time, so the higher the adsorption rate and the adsorption capacity.

\section{Conclusions}

The $C A$ s with different $R / C$ were prepared by a sol-gel method. The structure of $C A$ was characterized by SEM, and the control effect of R/C on the structure of CA was discussed. CA is composed of cross-linking nanoparticles, and its pore structure consists of micropores inside nanoparticles, mesopores, and macropores between the particles. The $\mathrm{R} / \mathrm{C}$ in the precursor solution affects the formation of particles and cross-linking between particles, which further impacts the structure and properties of CAs.

CV tests show that the prepared CA samples had good electrochemical properties. The 1030 sample has the highest specific capacity of $156 \mathrm{~F} / \mathrm{g}$ at the scanning rate of $10 \mathrm{mV} / \mathrm{s}$.

Through the CDI electrosorption experiments of the copper solution, the effects of anion species, the microstructure of $\mathrm{CAs}$ and operating conditions (including applied voltage and $\mathrm{Cu}^{2+}$ concentration) on the electrosorption capacity were explored. Moreover, the optimal parameter ranges for the corresponding conditions for the best adsorption capacity and removal amount were obtained. Among different anions, the order of adsorption effect is $\mathrm{SO}_{4}{ }^{2-}>\mathrm{NO}^{3-}>\mathrm{Cl}^{-}$. In different $\mathrm{CAs}$, the $\mathrm{CA}$ electrode with $\mathrm{R} / \mathrm{C}$ of 1000 has the best adsorption capacity. For different operating conditions, the best adsorption performance is obtained at the applied voltage of $1.2 \mathrm{~V}$ under the solution concentration of $100 \mathrm{mg} / \mathrm{L}$. The CDI adsorption experiments of copper ions by CAs in this work show that CAs have great development potential in the field of heavy metal ion treatment.

Author Contributions: Conceptualization, Z.Z.; formal analysis, C.Z.; funding acquisition, J.S.; investigation, Z.C., Z.Y. and Q.Q.; methodology, X.W.; resources, X.W.; supervision, Z.Z.; validation, J.S.; writing-original draft, Z.C., Z.Y. and Q.Q.; writing-review and editing, Z.Z.

Funding: This research was funded by the National Key Research and Development Program of China, grant number 2017YFA0204600, and National Natural Science Foundation of China, grant number 11874288, and Fundamental Research Funds for the Central Universities of Tongji University.

Conflicts of Interest: The authors declare no conflicts of interest.

\section{References}

1. Zhang, C.L.; Sun, N.N.; Xie, S.T.; Chen, Y.; Shen, S.B. Overview of heavy metal wastewater treatment technology and resource utilization. Mod. Chem. Ind. 2014, 34, 38-41.

2. Oren, Y. Capacitive deionization (CDI) for desalination and water treatment-Past, present and future (a review). Desalination 2008, 228, 10-29. [CrossRef] 
3. Xue, H.; Fu, Y.J.; Luo, A.Y.; Shen, J.; Wu, G.M.; Zhou, B. Research Progress of Carbon Aerogels and Their Application in Deionization. Mater. Rev. 2006, 20, 137-139.

4. Liu, D.; Shen, J.; Li, Y.J. Pore Structures of Carbon Aerogels and Their Effects on Electrochemical Supercapacitor Performance. Acta Phys.-Chim. Sin. 2012, 28, 843-849.

5. Zhang, C.; Wang, X.D.; Wang, H.Q.; Wu, X.L.; Shen, J. A positive-negative alternate adsorption effect for capacitive deionization in nano-porous carbon aerogel electrodes to enhance desalination capacity. Desalination 2019, 458, 45-53. [CrossRef]

6. Raut, P.; Liang, W.; Chen, Y.M.; Zhu, Y.; Jana, S.C. Syndiotactic Polystyrene-Based Ionogel Membranes for High Temperature Electrochemical Applications. ACS Appl. Mater. Interfaces 2017, 9, 30933-30942. [CrossRef] [PubMed]

7. Kong, Y.; Shen, X.D.; Cui, S. Nano Materials of Aerogels. Mater. China 2016, 35, 568-576.

8. Wang, X.B.; Luan, Z.Q.; Li, K.; Li, L.; Tang, T.F. Progress in Application of Aerogels as Adsorbents for Gas Purification. Mater. Rev. 2018, 32, 2214-2222, 2240.

9. Zhang, C.; Wang, X.D.; Wang, H.Q.; Wu, X.L.; Shen, J. Ambient Pressure-Dried Graphene-Composite Carbon Aerogel for Capacitive Deionization. Processes 2019, 7, 29. [CrossRef]

10. Qin, R.X.; Shen, J.; Xue, H.; Wu, G.M.; Zhou, B. Carbon aerogel electrode for the capacitive desalination of $\mathrm{NaCl}$ solution. Water Treat. Technol. 2005, 31, 53-55.

11. Meena, A.K.; Mishra, G.K.; Rai, P.K.; Rajagopal, C.; Nagar, P.N. Removal of heavy metal ions from aqueous solutions using carbon aerogel as an adsorbent. J. Hazard. Mater. 2005, 122, 161-170. [CrossRef] [PubMed]

12. Gabelich, C.J.; Tran, T.D.; Suffet, I.H. Electrosorption of inorganic salts from aqueous solution using carbon aerogels. Environ. Sci. Technol. 2002, 36, 3010-3019. [CrossRef] [PubMed]

13. Ying, T.Y.; Yang, K.L.; Yiacoumi, S.; Tsouris, C. Electrosorption of ions from aqueous solutions by nanostructured carbon aerogel. J. Colloid Interface Sci. 2002, 250, 18-27. [CrossRef] [PubMed]

14. Raut, P.; Swanson, N.; Kulkarni, A.; Pugh, C.; Jana, C.S. Exploiting arene-perfluoroarene interactions for dispersion of carbon black in rubber compounds. Polymer 2018, 148, 247-258. [CrossRef]

15. Li, J.; Wang, X.; Wang, H.; Wang, S.; Hayat, T.; Alsaedi, A.; Wang, X. Functionalization of biomass carbonaceous aerogels and their application as electrode materials for electro-enhanced recovery of metal ions. Environ. Sci. Nano 2017, 4, 1114-1123. [CrossRef]

16. Wang, H.; Zhang, D.; Yan, T.; Wen, X.; Zhang, J.; Shi, L.; Zhong, Q. Three-dimensional macroporous graphene architectures as high performance electrodes for capacitive deionization. J. Mater. Chem. A 2013, 1, 11778-11789. [CrossRef]

17. Noked, M.; Avraham, E.; Soffer, A.; Aurbach, D. The Rate-Determining Step of Electroadsorption Processes into Nanoporous Carbon Electrodes Related to Water Desalination. J. Phys. Chem. C 2009, 113, 237-246. [CrossRef]

(C) 2019 by the authors. Licensee MDPI, Basel, Switzerland. This article is an open access article distributed under the terms and conditions of the Creative Commons Attribution (CC BY) license (http://creativecommons.org/licenses/by/4.0/). 